\title{
Very early selection for solid wood quality: screening for early winners
}

\author{
Luis A. APIOLAZA* \\ School of Forestry, University of Canterbury, Private Bag 4800, Christchurch, New Zealand
}

(Received 21 November 2008; accepted 5 April 2009)

Keywords: wood stiffness / early selection / threshold trait / Pinus radiata

\begin{abstract}
- This article reviews the theoretical basis for indirect selection - where early selection is an example - and how correlated response is calculated.

- The review is followed by a description of issues as to the choice of selection criteria that could explain the lack of substantial progress on breeding for wood quality. These include: the autoregressive nature of selection criteria, overemphasizing the importance of basic density as selection criterion, ignoring age-related trends of wood properties, using rotation age rather than technical thresholds as objective traits and ignoring that not all grades have identical marginal economic value.

- Three data sets are either analyzed for the first time or reanalyzed under different assumptions, to explore the importance of these criticisms.

- Finally, the use of critical value thresholds as very early selection criteria is suggested and discussed in the context of improving intrinsic corewood quality.
\end{abstract}

Résumé - Sélection très précoce pour les propriétés du bois massif : détection précoce des individus les plus performants.

- Cet article passe en revue les bases théoriques des méthodes de sélection indirecte - parmi lesquelles figure la sélection précoce - et la manière dont le gain corrélé est calculé.

- Cette revue est suivie d'une description des problèmes liés au choix des critères de sélection et qui pourraient expliquer le manque de progrès substantiel suite à l'amélioration pour les propriétés du bois. Ceux-ci incluent l'auto-corrélation des critères de sélection, l'exagération de l'importance de la densité comme critère de sélection, l'oubli de l'évolution des propriétés du bois avec l'âge cambial, l'utilisation de l'âge de révolution comme caractère-cible plutôt que des seuils techniques et l'oubli que toutes les classes de produits n'ont pas la même valeur économique marginale.

- Trois jeux de données ont été soit analysés pour la première fois soit ré-analysés sous différentes hypothèses pour explorer l'importance de ces critiques.

- Enfin, l'utilisation de seuils critiques comme critères de sélection très précoce est suggérée et discutée dans le cadre de l'amélioration intrinsèque de la qualité du bois juvénile.

\section{INTRODUCTION}

Tree breeding aims to increase the frequency of superior phenotypes in plantations. This superiority is often defined in terms of additional profit per ha for a generic firm. Most modern programs rely on recurrent selection, implementing cycles of selection, mating and testing of trees, for which trees have to be assessed.

In breeding there is a clear distinction between traits that are targeted for breeding (objective traits) and the characters assessed in progeny trials (selection criteria) (Apiolaza and Greaves, 2001; Woolaston and Jarvis, 1995). Tree selection is performed on the latter. Although nominally some selection

*Corresponding author: luis.apiolaza@ canterbury.ac.nz criteria and objective traits may be identical (for example both could refer to total tree height, although at different ages), in practice they may refer to physiological processes under different degrees of genetic control in terms of heritability and causes of variation. For example, Balocchi et al. (1993) and Apiolaza and Garrick (2001) show the variation of genetic control with age for additive and dominance effects. Lopez et al. (2003) also show the variation of maternal effects with age.

Therefore, breeders practice indirect selection aiming for a correlated response on objective traits when selecting based on breeding values for selection criteria. In essence, irrespective of the method used to predict selection criteria (mass selection, selection index, or multivariate Best Linear Unbiased Prediction - BLUP), breeding values for objective traits 
are calculated using: (i) the correlations (often age-age) between selection criteria and objective traits; (ii) the correlation amongst selection criteria; and (iii) the relative economic weights for each trait. A cursory review of the literature will show that the former have received the bulk of attention from tree breeders.

Forest companies faced large product quantity and quality problems that convinced breeders to deal with wood properties. For many years wood basic density (DEN, $\mathrm{kg} \mathrm{m}^{-3}$ ) was presented as the canonical trait in wood quality research. It had many advantages: plenty of variation, a high degree of genetic control, and it was easy to assess. In fact some may argue that it became important because it was so easy to assess (Apiolaza, 2008). Pine breeders in several breeding programs have included DEN as one of their selection criteria (see below); in spite of this, intrinsic wood quality has not changed significantly.

In the case of structural wood, grades - and consequently prices - are partly defined by wood stiffness measured as modulus of elasticity (MoE, GPa). Cave (1968) presented the theory relating microfibril angle $\left(\mathrm{MFA},{ }^{\circ}\right)$ to $\mathrm{MoE}$ and applied the model to radiata pine. Megraw et al. (1999) and Evans and Ilic (2001) showed that the combination of MFA and DEN explains over $90 \%$ of MoE variation. In addition there are agerelated trends for these traits (Burdon et al., 2004), which in turn may affect optimal selection age.

In this document I first explore the theoretical basis for indirect selection - where early selection is an example - and how the correlated response is calculated. Then I cover issues as to the choice of selection criteria that could explain the lack of substantial progress on breeding for wood quality. At this point three data sets are either analyzed for the first time or reanalyzed under different assumptions. Finally, I discuss the uses of selection criteria and suggestions as to how to approach very early selection and breeding for wood quality traits.

\section{Indirect selection, correlated response}

Searle (1965) described the effect of indirect selection on correlated traits, which depends on the heritabilities for each trait as well as on the correlation between the traits. This work has been extended by several authors to cover a more generic situation.

Tree breeding has a multivariate nature, aiming to simultaneously improve several traits. A breeding objective $(H)$ is then defined as the combination of breeding values for $n$ objective traits $\left(a_{\mathrm{i}}\right)$ and their relative economic weights $\left(w_{\mathrm{i}}\right)$, usually in a linear fashion. Breeding values for $m$ selection criteria $\left(s_{\mathrm{i}}\right)$ and index weights $\left(b_{\mathrm{i}}\right)$ are combined to form a selection index $I$. The objective and index can be expressed in scalar and matrix forms as:

$$
\begin{aligned}
H & =w_{1} a_{1}+w_{2} a_{2}+\ldots+w_{\mathrm{n}} a_{\mathrm{n}}=\boldsymbol{w}^{\prime} \boldsymbol{a} \\
I & =b_{1} s_{1}+b_{2} s_{2}+\ldots+b_{\mathrm{m}} s_{\mathrm{m}}=\boldsymbol{b}^{\prime} \boldsymbol{s}
\end{aligned}
$$

where $\boldsymbol{w}, \boldsymbol{a}, \boldsymbol{b}$ and $\boldsymbol{s}$ are vectors of economic weights, objective traits, index coefficients and selection criteria respectively.
Note that the number of traits and criteria do not need to be equal to each other. Index weights are calculated as to maximize the correlation between $H$ and $I$ (Hazel, 1943):

$$
\boldsymbol{b}=\boldsymbol{P}^{-1} \boldsymbol{G} \boldsymbol{w}
$$

where $\boldsymbol{P}$ and $\boldsymbol{G}$ refer respectively to the phenotypic and additive genetic covariance matrices. This relationship was first derived assuming that the selection criteria were phenotypic observations of the objective traits; i.e. criteria and traits were identical. However, it was later generalized to distinct criteria and traits (Binet, 1965; Lin, 1978), to all types of information on relatives (see examples in Van Vleck, 1993) and to breeding values predicted using BLUP as selection criteria (Schneeberger et al., 1992). Coefficients for the latter are calculated as:

$$
\boldsymbol{b}=\boldsymbol{G}_{\mathrm{ss}}^{-1} \boldsymbol{G}_{\mathrm{so}} \boldsymbol{w}
$$

where $\mathbf{G}_{\mathrm{ss}}$ is the additive covariance matrix for the selection criteria and $\mathbf{G}_{\mathrm{so}}$ is the additive covariance matrix between the selection criteria and objective traits.

The amount of genetic gain $\left(\Delta_{\mathrm{G}}\right.$, aka response to selection) can be predicted by using a simple function - often termed breeders' equation - of three elements: selection intensity $(i)$, accuracy of prediction (the correlation between the index and the objective, $r_{\mathrm{IH}}$ ) and the variability of the trait (or combination of traits) under selection $\left(\sigma_{\mathrm{H}}^{2}\right)$ :

$$
\Delta_{\mathrm{G}}=i r_{\mathrm{IH}} \sigma_{\mathrm{H}}^{2} \text {. }
$$

It is clear that increasing any of the three terms will lead to higher $\Delta_{\mathrm{G}}$. However, barring an infusion of new material (e.g., provenances), the variance of the breeding objective is often considered as fixed. This leaves only increasing selection intensity and/or accuracy of prediction as means for improving gain.

When working with traits with high measurement costs (e.g. wood quality traits), the main barrier against a high effective selection intensity is the number of trees that a breeder can afford to assess. This situation should have a large influence on the selection of appropriate evaluation tools (either phenotypic or molecular). As an example, for a given trait breeders could choose from wet chemistry, SilviScan, Near Infrared Reflectance spectroscopy (NIR) and acoustic assessments. These techniques - which are presented in more detail in the following section - vary on reliability of the results and cost, creating a choice where increasing resolution of assessment implies measuring fewer trees and obtaining a lower selection intensity.

\section{THE STATUS QUO ON EARLY SELECTION}

\subsection{Phenotypic information}

Since the early 1990s the predominant form of wood quality assessments for radiata pine (and many other commercial species) progeny trials has been the use of increment cores. Basic density - the most popular trait - is estimated by the 
water displacement method after subjecting the green cores to several resaturation cycles (Smith, 1954). Most of the time there is a single average DEN per core, although some times the cores have been partitioned into five-rings sections to study the change of DEN with age. However, it is hard to explain the observed range for MoE based on DEN variability (Tsehaye et al., 2000).

Tree breeders have then run univariate analyses, mostly ignoring any experimental features besides replicates, because the small number of samples is not enough to estimate other constraints to randomization (e.g. plots). If trials have more than one assessment or the cores have been partitioned, then breeders have estimated age-age correlations, often recurring to the sum of assessments to estimate the covariance ${ }^{1}$ (e.g., Dungey et al., 2006). This relationship should be a good approximation if there are no missing observations. A more formal approach would be to treat wood quality in a longitudinal analysis framework, as presented by Apiolaza and Garrick (2001).

Another extreme on the study of wood properties and their effect on end-products are processing studies. For example, Shelbourne (1997) reports on over 90 traits (wood properties, kraft and thermomecanical pulp and paper, and sawn timber) obtained for two sets of 10 clones. However, the high cost of this type of studies often leads to small sample sizes and imprecisely estimated relationships between quality traits and end-products. These studies should also involve sampling corewood to estimate properties that can be used as early selection criteria.

There is mounting evidence on the chemical basis of many important wood quality traits. While traditionally they have been estimated using 'wet chemistry', NIR has dominated the genetic evaluation of Eucalyptus (see Raymond, 2002, and references therein). Initially NIR focused on properties related to pulping (e.g. Raymond and Schimleck, 2002; Raymond et al., 2001); however, its use has been extended to any other trait that could have a chemical basis; for example wood stiffness (Schimleck et al., 2002) and MFA (Schimleck et al., 2005). NIR can also be used to estimate a more general chemical composition (Schimleck et al., 2005), including galactan content, which is related to longitudinal shrinkage (Floyd and Stanish, 2004) and, finally, to dimensional stability of the wood. Frequently NIR analyses are conducted at the increment core level, although sometimes cores are split to get corewood and outerwood readings.

Corewood MoE is mostly determined by MFA, but this property is expensive and time consuming to assess (Huang et al., 2003). Acoustic tools - based on stress wave, ultrasound velocity or sonic resonance - provide an easy estimation of $\mathrm{MoE}$, that can be used for log segregation and tree selection (Lindström et al., 2002). Acoustics can be used for screening at a very early age and be related to a number of properties

\footnotetext{
${ }^{1}$ If the first assessment is termed $x$ and the second $y$, then follows that $\operatorname{Var}(x+y)=\operatorname{Var}(x)+\operatorname{Var}(y)+2 \operatorname{Cov}(x, y)$. If one runs the univariate analyses and then the analysis for the sum, it is possible to calculate the value for the covariance between assessments.
}

like MoE, dimensional stability, fiber length, etc (Huang et al., 2003).

During the last five years there has been a surge of work involving SilviScan (or similar tools) data for DEN and MFA at the ring level. SilviScan is used to analyze a $2 \mathrm{~mm}$ thick polished flitch, cut along the length of an increment core. The samples are scanned from pith to bark using X-ray densitometry, X-ray diffractometry and image analysis to measure or predict a range of properties. Different researchers have opted for using an average core value (e.g., Apiolaza et al., 2005), modelling the evolution of the trait (e.g., Apiolaza and Garrick, 2001; Isik et al., 2008; Zamudio et al., 2002) or calculating age-age correlations for area-weighted averages (e.g., Dungey et al., 2006; Kumar et al., 2006; Wu et al., 2007). These studies have assumed that an appropiate goal for a breeding program is to improve an average value for the trait at rotation age. Kumar et al. (2006) even state as a drawback that 'early selection for MoE could yield substantial gain in corewood MoE but only small gains, if any, in outerwood MoE (especially for rings 21-30)'. However, we will see below that this may be highly desirable.

\subsection{Molecular information}

It is impossible to cover a topic like early selection without alluding to the 'useful flirtation of quantitative and molecular genetics', borrowing the term from Gibson (1999). During the early 1990s the molecular genetics revolution started having a profound effect on research applied to tree breeding. Until then, only phenotypic information was available for the prediction of genetic value.

In the wood quality front, basic density, cellulose and lignin content have been the most targeted traits by molecular tools. At the same time, it is these traits that have benefited the most from the advances on phenotyping using NIR (see above). As pointed out in equation (5), response to selection is proportional to accuracy of prediction; thus, finding quantitative trait loci (QTL) in situations of low accuracy could lead to different (and higher gain) selection strategies (O'Malley and McKeand, 1994). However, (i) it is easier to find QTL of large effects for high heritability traits, defeating part of the appeal of using molecular techniques and (ii) it requires large number of individuals for each particular cross (often unavailable in a traditional progeny testing setting).

Fernando and Grossman (1989) extended BLUP to account for phenotypic and marker information (MBLUP) in a generic genetic evaluation. Nevertheless, marker assisted selection (MAS), based on the association of markers and QTL seems to work primarily for within-family selection, limiting its practical use in breeding programs (O'Malley and McKeand, 1994; Grattapaglia and Kirst, 2008).

The importance of the role of molecular information cannot be denied for quality control of crosses, the study of evolutionary processes and the understanding of fundamental biological processes. However, Grattapaglia and Kirst (2008) explain that in Eucalyptus 'the application of QTL information for directional selection is still an unfulfilled promise'. The situation 
Table I. Wood quality criteria used for early selection in five countries. The number of breeders surveyed is between brackets. Only criteria and tools frequently used are listed.

\begin{tabular}{|c|c|c|c|c|}
\hline Country & Species & Criteria & Age & Operational \\
\hline \multirow[t]{4}{*}{ Australia (2) } & Pinus radiata & Basic density (core) & $6-8$ & Yes \\
\hline & & Basic density (Pilodyn) & $6-8$ & Occasional \\
\hline & & MoE (Fakkop) & $6-8$ & Yes \\
\hline & & MoE, MFA (SilviScan) & $10-15$ & Research \\
\hline \multirow[t]{3}{*}{ Chile (3) } & Pinus radiata & Basic density (core) & 8 & Yes \\
\hline & & MoE (TreeTap, Fakkop) & 8 & Occasional \\
\hline & & Lignin content (NIR) & 8 & Occasional \\
\hline \multirow[t]{4}{*}{ New Zealand (1) } & Pinus radiata & Basic density (core) & $7-8$ & Yes \\
\hline & & MoE (TreeTap) & $6-8$ & Yes \\
\hline & & MoE, MFA (SilviScan) & $15-20$ & Research \\
\hline & & Chemistry (NIR) & Various & Research \\
\hline \multirow[t]{2}{*}{ South Africa (1) } & Pinus & Basic density (pilodyn) & 8 & Yes \\
\hline & Eucalyptus & Basic density (pilodyn) & 5 & Yes \\
\hline \multirow[t]{4}{*}{ USA (2) } & Pinus taeda & Basic density (core) & 8 & Yes \\
\hline & Pinus taeda & MoE (acoustics) & 8 & Occasional \\
\hline & Pinus taeda & Wood chemistry (NIR) & 8 & Occasional \\
\hline & Pinus elliottii & Basic density (core) & 8 & Yes \\
\hline
\end{tabular}

in pines is similar, in spite of very optimistic (even unrealistic) calculations published for radiata pine earlier this decade (e.g. Wilcox et al., 2001, estimated a 9\% internal rate of return for the investment). Grattapaglia and Kirst (2008) give a number of reasons for this: (i) the high heterogeneity and linkage equilibrium of breeding populations, (ii) the lack of simply inherited traits that could be easily targeted and (iii) the difficulty to develop inbred lines to better understand the genetic architecture of traits. In addition, the advent of simple and quick phenotyping techniques for wood quality (e.g. NIR and acoustics) has rendered superfluous some of the arguments for the use of molecular techniques for wood quality screening (Dario Grattapaglia, personal communication).

In spite of the previously reported lackluster results, there are reasons to be optimistic on more advanced, future applications of molecular genetics. Decreasing genotyping costs make now feasible the characterization of individuals using thousands of single nucleotide polymorphisms (SNPs). Meuwissen et al. (2001) put forward the prediction of total genetic value using thousands of markers achieving genomewide coverage. This work has been extended by several researchers in animal evaluation (e.g., Calus et al., 2008; Fernando et al., 2007; Gianola et al., 2006), where genomewide selection is becoming mainstream. Schaeffer (2006) compared breeding strategies based on traditional, phenotypebased evaluation to evaluation based on markers with whole genome coverage. His results suggest an immense cost reduction and a large increase on accuracy of selection, although it still reads too optimistic.

A potentially successful application of these technologies in animal breeding will not necessarily translate in the same way to tree breeding. There are some concerns on the practicalities of genome-wide selection in trees, particularly with respect to the number of markers - and cost - involved to achieve full genome coverage (Josquin Tibbits, personal communication).
This requirements will probably have to be simulated before embarking in a major investment in this area.

\subsection{What are breeding programs actually doing?}

I contacted breeders in Australia, Chile, South Africa and United States to obtain information on past and current practices for early selection. As some people requested confidentiality, the responses are presented aggregated by country. Assessment ages are only approximate.

A quick review of Table I shows that there are many commonalities on the efforts being put on wood quality. The main wood quality selection criterion is DEN, underlying that (i) some programs serve primarily the pulp and paper industry (e.g. Chile and USA) and (ii) many people still consider that DEN is closely related to most relevant wood properties. Assessment is performed using increment cores around age 7-8 and all programs target average DEN at rotation age.

It is important to highlight that until the early 1990s most radiata pine breeding programs targeted only basic productivity $\left(\mathrm{m}^{3} \mathrm{ha}^{-1}\right)$ and stem straightness. For example, only in 1997 the Chilean second generation radiata pine included DEN breeding values. Furthermore, trees have been screened for stiffness and lignin content only during the last couple of years.

\section{ISSUES WITH SELECTION CRITERIA}

Typical selection criteria in tree breeding include growth traits (dbh, height or volume, for example) and weighted averages, by ring area, of wood quality traits like DEN or MoE. Most breeding objectives consider the expression of these traits at rotation age.

While many breeding programs can show positive results for growth and form traits, there is a lack of substantial 
progress on intrinsic wood quality, with the possible exception of DEN for pulp regimes. I posit that we have ignored a number of features of the problem that could be exploited to increase gain on intrinsic quality by using time or stem size to reach a threshold value:

1. The class of traits assessed in breeding programs tends to induce an autoregressive process, with a coefficient that affects the chances of successfully performing early selection.

2. The importance of the effect of DEN on several wood quality traits has been overemphasized, very likely because of its ease of assessment.

3. There are known time-related trends of wood properties; for example, there is a reduction of MFA with age (e.g. Cave, 1968).

4. For several wood properties there are technical thresholds that define end-product or grades. For example, machine stress grading in radiata pine defines value by stiffness thresholds.

5. Not all grades or products have identical marginal economic value; that is, moving from grade $\mathrm{A}$ to $\mathrm{B}$ may not be worth the same as moving from grade B to C (e.g. Sorensson and Shelbourne, 2005).

6. There is a large amount of wood that does not meet the minimal requirements for solid timber, and it is downgraded to 'industrial' use (pulp and paper, low quality packaging, etc). That is, the economic effect of improving industrial grade wood may be much larger than for improving already acceptable wood (e.g. Gaunt, 1998).

I will now expand on some of these issues.

\subsection{The effect of an autoregresive process}

Growth traits and weighted averages of wood quality induce an autoregressive process, where the breeding values of new measurements $\left(a_{\mathrm{ij}}\right)$ depend on previous assessments $\left(\rho a_{\mathrm{ij}-1}\right)$ plus an innovation term $\left(\alpha_{j}\right.$, see Apiolaza and Garrick, 2001, for a more detailed explanation):

$$
a_{\mathrm{ij}}=\rho a_{\mathrm{ij}-1}+a_{\mathrm{j}} .
$$

Figure 1 depicts the correlation between two assessments for autoregressive processes using autocorrelations (i.e. correlation between measurements one year apart) of $0.95,0.90$ and 0.85 for varying lags between assessments. It is easy to see that breeders will struggle to perform very early selection and obtain a good correlated response at rotation age, unless the autocorrelation coefficient is very high. As an illustration, if the autocorrelation is anything under 0.95 , a lag of $15 \mathrm{y}$ (e.g., measurements at 5 and $20 \mathrm{y}$, or at 10 and $25 \mathrm{y}$ ) will make the association between selection criterion and objective trait almost non-existent.

The answer to this problem has often been to delay selection to between one quarter and one third of rotation age (White et al., 2007, p. 519). This selection age is chosen in such a way that maximizes gain per unit of time or, more appropriately, net present value of the breeding program (e.g.,

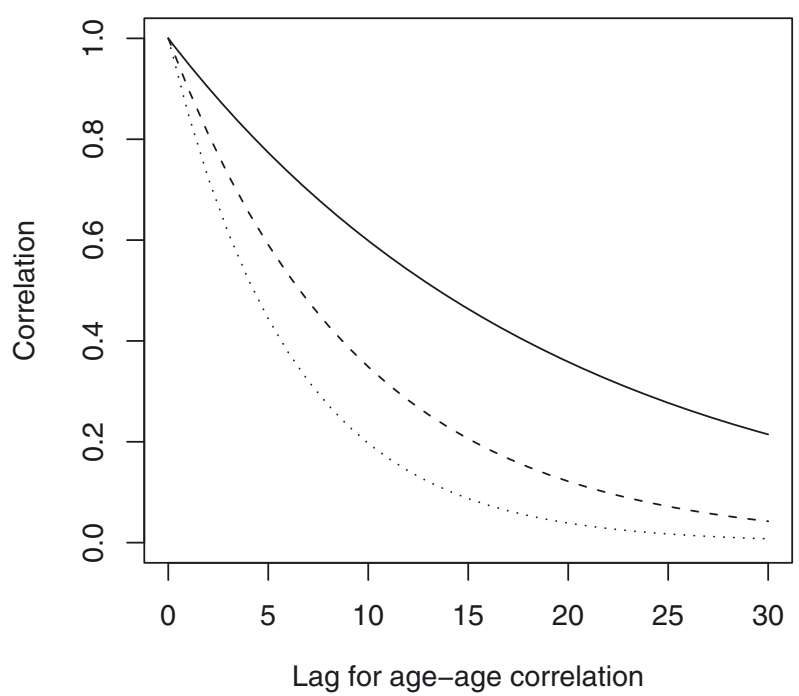

Figure 1. Correlation between a generic selection criterion and objective trait, assuming an autoregressive process with correlation 0.95 (solid line), 0.90 (dashed line) and 0.85 (dotted line) between measurements one year apart. The correlation becomes almost zero for fifteen years between juvenile and adult assessments (a common lag in tree breeding) if the autocorrelation is under 0.95 .

Newman and Williams, 1991). The status quo is, however, to calculate the efficiency of early selection in relation to traits expressed at rotation age. While this may be reasonable for many growth traits, it imposes an unnecessary delay for several wood quality traits, which are amenable to be considered as critical threshold traits.

\subsection{The effect of DEN on MoE at current selection age}

The New Zealand Wood Quality Initiative collected data on DEN and squared acoustic velocity ( $v^{2}$ an estimate of wood $\mathrm{MoE}$ ) from 60 permanent sample plots and 13 ages. Figure 2A presents a regression of 'acoustic $\operatorname{MoE}$ ' $\left(v^{2}\right)$ on DEN for a sample of 635 logs. This type of positive relationship guided breeding efforts for structural wood for several years; however, once age is taken into account we are faced with an example of ecological correlation. Figure 2B splits the dataset into three age groups: under $15 \mathrm{y}$, greater than 15 and lower than $25 \mathrm{y}$, and over 25 years of age. There is still a good relationship between $v^{2}$ and DEN for trees over 15 years old; in contrast, the relationship breaks down under age 15 . It is important to remember that the assessment of progeny trials in most Pinus radiata breeding programs occurs between 7 and 8 years of age. As such, selection of MoE based on DEN is far from perfect. These changes of the relationship between $v^{2}$ and DEN with age have been reported elsewhere by Chauhan and Walker (2006).

The previous example tackles the relationship at a phenotypic level. However, what is the situation at the genetic level? Currently the New Zealand Radiata Pine Breeding Company (RPBC) includes over 60 progeny trials in its genetic evaluation process. Nevertheless, only five trials have been assessed 

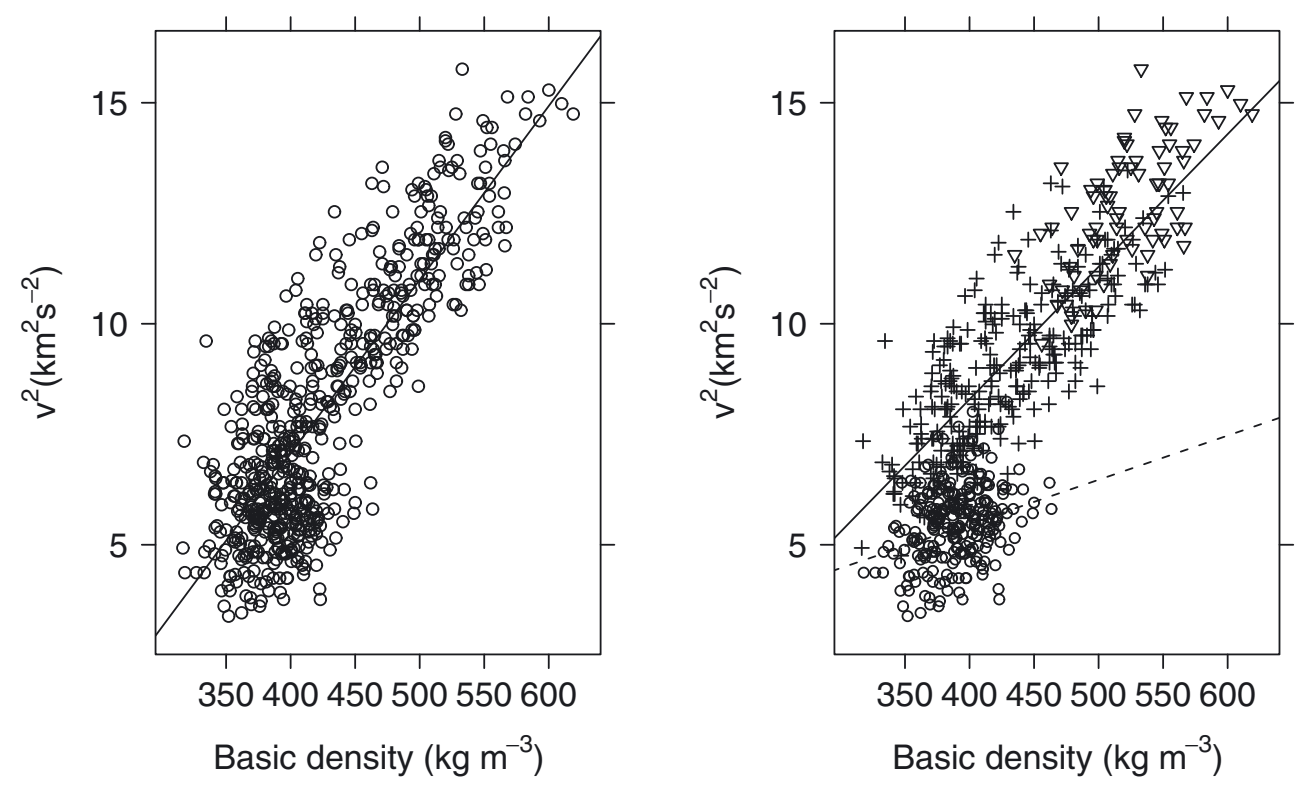

Figure 2. Relationship between $\left(v^{2}\right)$, an estimate of MoE, and DEN for 635 logs. Part A shows the relationship between the variables when age is ignored $\left(R^{2}=0.68\right)$. Part B separates the observations in three age classes: under 15 years $(\mathrm{o})$, greater than 15 and lower than 25 years $(+)$, and over 25 years of age $(\nabla)$. The explained proportion of variation is much lower for young trees $\left(R^{2}=0.08\right)$.

for both DEN and acoustic velocity (using TreeTap, a timeof-flight tool). The poor connectedness between sites in this dataset provides what can be considered as five independent samples of the association between DEN and MoE.

At each site a univariate individual tree model was fitted where DEN and 'acoustic MoE' $\left(y_{\mathrm{ijk}}\right)$ were explained with the fixed effect of the overall mean $(\mu)$, and the random effects of replicate $i\left(r_{\mathrm{i}}\right)$, set $j\left(s_{\mathrm{j}}\right)$, additive genetic effect $\left(a_{\mathrm{i}}\right)$ and residuals $\left(e_{\mathrm{i}}\right)$. Controlled pollinated trials also included a random family effect $\left(f_{1}\right)$ that estimates one quarter of dominance variance:

$$
y_{\mathrm{ijk}}=m+r_{\mathrm{i}}+s_{\mathrm{j}}+a_{\mathrm{k}}+f_{\mathrm{l}}+e_{\mathrm{k}}
$$

Then a bivariate analysis of DEN and MoE was fitted, extending the model to by 'stacking up' the vectors for two traits. The residuals are then defined as $\boldsymbol{R}_{0} \otimes \boldsymbol{I}$ and the additive genetic effects as $\boldsymbol{G}_{0} \otimes \boldsymbol{A}$, where $\boldsymbol{R}_{0}$ is the individual residual covariance matrix, $\boldsymbol{G}_{0}$ is the additive genetic covariance matrix, $\boldsymbol{A}$ the numerator relationship matrix, $\otimes$ the Kronecker product and $\boldsymbol{I}$ is an identity matrix:

$$
\boldsymbol{R}_{0}=\left[\begin{array}{cc}
\sigma_{\mathrm{e}_{\mathrm{DEN}}}^{2} & \sigma_{\mathrm{e}_{\mathrm{DM}}} \\
\sigma_{\mathrm{e}_{\mathrm{DM}}} & \sigma_{\mathrm{e}_{\mathrm{MOE}}}^{2}
\end{array}\right] \quad \boldsymbol{G}_{0}=\left[\begin{array}{cc}
\sigma_{\mathrm{a}_{\mathrm{DEN}}}^{2} & \sigma_{\mathrm{a}_{\mathrm{DM}}} \\
\sigma_{\mathrm{a}_{\mathrm{DM}}} & \sigma_{\mathrm{a}_{\mathrm{MOE}}}^{2}
\end{array}\right]
$$

were $\sigma_{\mathrm{a}_{\mathrm{DEN}}}^{2}$ and $\sigma_{\mathrm{a}}^{2}$ are additive genetic variances, $\sigma_{\mathrm{e}_{\mathrm{DEN}}}^{2}$ and $\sigma_{\mathrm{e}_{\mathrm{MOE}}}^{2}$ are residual variances, and $\sigma_{\mathrm{aDM}}$ and $\sigma_{\mathrm{e}}$ are the additive genetic and residual covariances between the traits. Replicates, sets and family effects for each trait - much smaller than additive and residuals effects - were fitted using diagonal matrices with $\sigma_{\mathrm{r}_{\mathrm{i}}}^{2}, \sigma_{\mathrm{s}_{\mathrm{i}}}^{2}$ and $\sigma_{\mathrm{f}_{\mathrm{i}}}^{2}$ respectively to avoid convergence problems. Heritability for each trait was calculated as (replacing $i$ by DEN and MoE):

$$
h_{\mathrm{i}}^{2}=\frac{\sigma_{\mathrm{a}_{\mathrm{i}}}^{2}}{\sigma_{\mathrm{r}_{\mathrm{i}}}^{2}+\sigma_{\mathrm{s}_{\mathrm{i}}}^{2}+\sigma_{\mathrm{a}_{\mathrm{i}}}^{2}+\sigma_{\mathrm{f}_{\mathrm{i}}}^{2}+\sigma_{\mathrm{e}_{\mathrm{i}}}^{2}} .
$$

The additive genetic correlation between DEN and MoE was calculated as:

$$
r_{\mathrm{DM}}=\frac{\sigma_{\mathrm{a}_{\mathrm{DM}}}}{\sqrt{\sigma_{\mathrm{a}_{\mathrm{DEN}}^{2}}^{2} \sigma_{\mathrm{a}_{\mathrm{MOE}}}^{2}}} .
$$

Data preparation and plotting for all analyses was performed with the statistical software R (R Development Core Team, 2008), while quantitative genetic analyses were ran using ASReml (Gilmour et al., 2002).

Table II shows a summary of the genetic parameters for both traits. It is possible to see that the genetic correlation between traits deteriorates with age. Thus, outerwood correlations are high at age $16(0.71)$, and moderate and high at age 12 (0.36 and 0.68). A similar situation for radiata pine in Australia has been reported by Wielinga et al. (2009), with correlation of 0.64 at 12 years of age. The situation changes for corewood correlations (at the time of selection for breeding purposes), which are either weak and non-significant $(0.21)$ or take a negative value $(-0.63)$.

\subsection{Inheritance of an MoE threshold}

A progeny trial in Kaingaroa Forest compartment 1350 including 50 open-pollinated families, with a total of 428 trees - was first sampled for a densitometry analysis using SilviScan in 1999, and the DEN results were presented as a case study for longitudinal analysis by Apiolaza and Garrick 
Table II. Heritability for DEN $\left(h_{\mathrm{DEN}}^{2}\right)$ and 'acoustic MoE' $\left(h_{\mathrm{MoE}}^{2}\right)$, and genetic correlation between DEN and 'acoustic MoE' $\left(r_{\mathrm{DM}}\right)$ for five radiata pine progeny trials.

\begin{tabular}{|c|c|c|c|c|c|}
\hline & FR260_1 & FR399_3 & FR38_2 & FR203_2 & RO2111_1 \\
\hline $\mathrm{OP} / \mathrm{CP}$ & $\mathrm{CP}$ & $\mathrm{CP}$ & $\mathrm{OP}$ & $\mathrm{OP}$ & $\mathrm{OP}$ \\
\hline$n$ families & 27 & 113 & 58 & 68 & 87 \\
\hline$n$ trees & 702 & 1867 & 578 & 838 & 1424 \\
\hline $\operatorname{age}_{\text {DEN }}$ & 7 & $1-5$ & $6-10$ & 8 & $6-10$ \\
\hline$h_{\mathrm{DEN}}^{2}$ & $0.28(0.19)$ & $0.74(0.11)$ & $0.50(0.16)$ & $0.61(0.11)$ & $0.61(0.12)$ \\
\hline $\operatorname{age}_{\mathrm{MoE}}$ & 7 & 7 & 12 & 12 & 16 \\
\hline
\end{tabular}

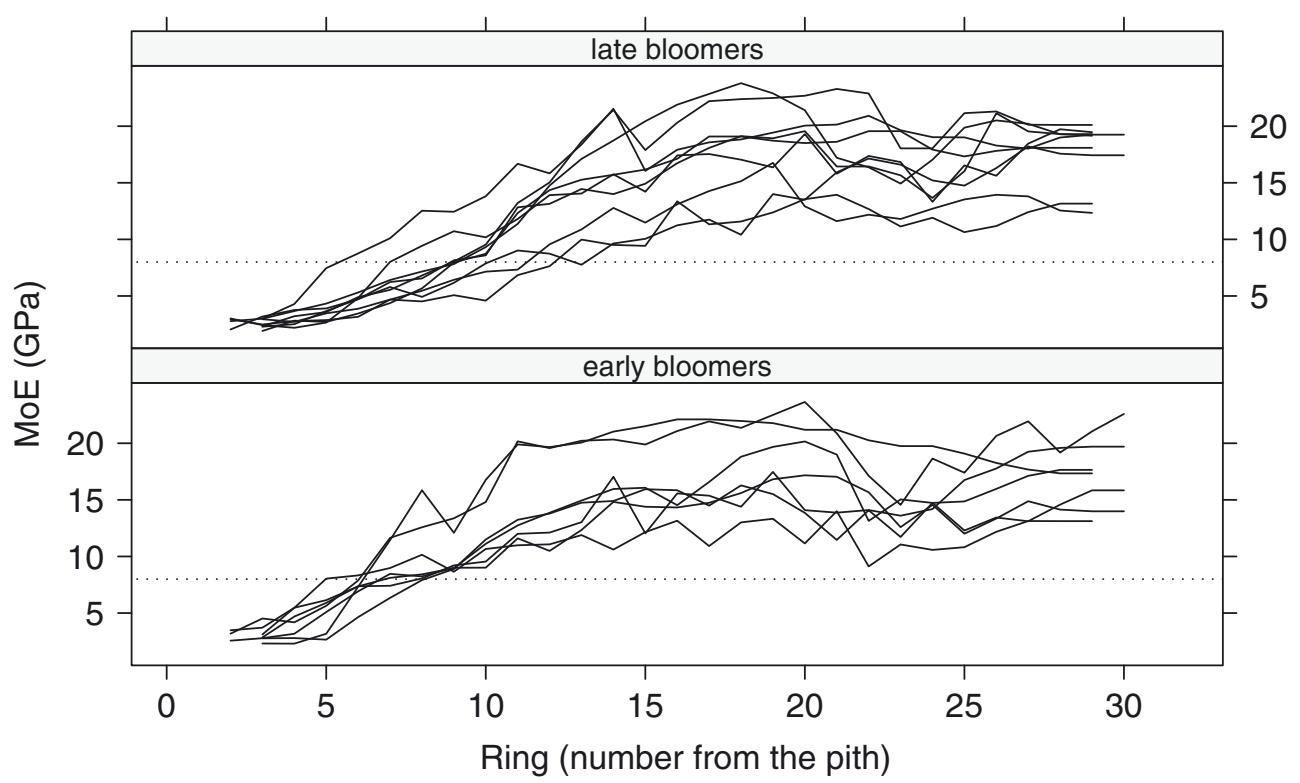

Figure 3. Pith to bark change of SilviScan-estimated MoE for the trees of the best ('early bloomers') and worst ('late bloomers') families from cores covering 28 y. Notice the large within-family variation, particularly for the 'late bloomers'. The best trees achieve the 8 GPa threshold by age 5 .

(2001). Sampling was repeated in 2004, when DEN and MFA were directly assessed using SilviScan. These values were used to obtain an approximation of MoE, which was analyzed using a univariate approach (Dungey et al., 2006). In contrast, in this paper threshold values (first ring with an $\mathrm{MoE} \geqslant 8 \mathrm{GPa}$ ) instead of weighted averages were obtained for each tree in the 2004 sampling. The $8 \mathrm{GPa}$ threshold considers a minimum stiffness of $6 \mathrm{GPa}$ (to qualify as structural wood in New Zealand), plus a $2 \mathrm{GPa}$ margin to cope with potential stiffness reductions caused by branches.

Analyses for threshold values $\left(y_{\mathrm{i}}\right)$ were conducted using an individual tree model fitting overall mean $(\mu)$, as well as random replicate $\left(r_{\mathrm{i}}\right)$, additive genetic $\left(a_{\mathrm{j}}\right)$, and residual $\left(e_{\mathrm{j}}\right)$ effects:

$$
y_{\mathrm{i}}=\mu+r_{\mathrm{i}}+a_{\mathrm{j}}+e_{\mathrm{j}}
$$

Expected value and variance for the model equation are $E\left[y_{\mathrm{i}}\right]=\mu$ and $V\left[y_{\mathrm{i}}\right]=\sigma_{\mathrm{r}}^{2}+\sigma_{\mathrm{a}}^{2}+\sigma_{\mathrm{e}}^{2}$ respectively. That is, the model is additive and with zero covariance between the terms.

Heritability $\left(h^{2}\right)$, the degree of additive genetic control, was calculated using the standard formula:

$$
h^{2}=\frac{\sigma_{\mathrm{a}}^{2}}{\sigma_{\mathrm{r}}^{2}+\sigma_{\mathrm{a}}^{2}+\sigma_{\mathrm{e}}^{2}} .
$$

There are three positive results from this analysis. Firstly, heritability for first ring meeting an $8 \mathrm{GPa}$ threshold is moderate to high $\left(h^{2}=0.45\right.$ with a standard error of 0.16$)$, in line with other wood quality traits. Secondly, there is plenty of between and within-family variation to exploit in this trait. As an example, Figure 3 presents within-family variation for the first and last family to reach, on average, the $8 \mathrm{GPa}$ threshold. Finally, once trees reach the threshold they tend to stay above it for the duration of rotation. 


\section{A PATHWAY TO VERY EARLY SELECTION}

It is time to propose an alternative to overcome the weaknesses of the current approaches to breeding for solid wood quality. Considering the previously discussed 'issues on selection criteria' we can use the following guidelines:

1. There is little value on improving outerwood, whereas improving corewood would increase the proportion of structural grade wood as well as reduce the corewoodouterwood MFA gradient, making wood more stable. Thus, if we target only corewood we are in fact changing the objective trait and improving the chances of success.

2. Wood basic density itself is not enough to predict corewood solid wood quality performance. Acoustic tools - either by themselves or in combination with basic density will provide much better response to selection.

3. Breeders could either take the average value at a younger age - e.g. ten years for radiata pine - or, better, aim for a 'first past the post' (early winners) approach. In the latter methodology, trees could be evaluated at an arbitrarily early age, say four years, and only trees reaching a threshold value would be selected. This strategy relates to the analysis presented in the 'inheritance of an MoE threshold' subsection.

4. Rather than relying on a data dense approach such as SilviScan, breeders could use simpler techniques like acoustic assessment, that provide a single value representing the properties of either the whole stem (using resonance) or the outermost rings (using time of flight). From a quantitative genetics viewpoint, it would involve a binomial analysis where the response variable is 1 (tree meets the threshold) or 0 (it does not).

5. Very early selection will impose some accuracy trade-offs, particularly if breeders insist on comparing results with traits expressed later in rotation. However, simple and cheap assessment techniques will permit screening a much larger number of trees (e.g. Isik and $\mathrm{Li}, 2003$ ), de facto increasing selection intensity and compensating for lower accuracy.

6. Breeders may be better served by screening rather than selection techniques, particularly when dealing with production populations. For many traits identifying the worst trees is easier than selecting the best ones; both approaches will contribute to improve the average value for a population.

Concerning the choice of selection criteria and objective traits, Isik et al. (2008) comment that current methods for measuring MFA are too expensive to use on large samples in tree improvement programs and suggest that marker aided selection could be used as indirect selection. They are also apologetic about having assessed only the first 10 rings. While forest growers are not yet paid for MFA, lumber grades take account of wood stiffness and stability. MFA certainly contributes to these traits, but when one considers the trends of MFA with age, most of the problems arise from excessively high MFA (above $30^{\circ}$ ) very early on the life of a tree.

Breeders may be hesitant to focus only on corewood quality, worrying about the consequences of ignoring outerwood.
However, Myszewski et al. (2004) found non-significant genetic correlations for assessments of MFA between rings 4 and 5, and 19 and 20. They pointed out that the effect of early selection on outerwood would be either beneficial or inconsequential. Either way, selection at very early ages for MFA would result in producing 'prime' material in the center of the stem (Lima et al., 2004). A reduction of corewood MFA would also reduce the MFA gradient, improving wood dimensional stability and stiffness (Walker and Butterfield, 1995; Yamashita et al., 2009).

For young trees there is a good relationship between MFA and acoustic velocity (an easy to assess and low-cost selection criterion) that could be used as a surrogate for MFA. If there were some interest in tracking the change of this characteristics one could conceivable assess acoustic velocity in different years, creating a matryoshka doll of wood quality assessments.

There are techniques already under development that exacerbate the early expression of wood quality problems, exploiting formation of compression wood for selection purposes under one year of age (Nakada, 2007; Apiolaza et al., 2008). This is a clear example of very early screening of radiata pine for wood stiffness that would fit in the proposed strategy. The approach suggested in this paper could be easily applied to other species and traits. For example, Chauhan (2008) points out the effectiveness of a 'pairing test' for the screening of Eucalyptus trees for growth stresses, sawing logs along the pith and measuring the magnitude of outward bending of the two halfrounds. This technique has been successfully used with trees as small as $20 \mathrm{~mm}$ diameter (S. Chauhan, personal communication).

A side effect of very early selection with a 'first past the post' approach is the potential reduction of generation interval and, more important, shorter rotation age (say 18-20 y). For example, in New Zealand rotation age has been extended to 30 or more years to compensate for the low quality (and value) of corewood. Reducing the number of rings not meeting a quality threshold improves profitability of shorter rotations.

A straightforward criticism to the proposed approach is that breeders may still need to wait for other traits (e.g. growth) to be expressed at, or near, rotation age. However, in many breeding programs genetic material was initially evaluated for growth and form, but not for wood quality. Thus, there is an opportunity to perform backwards selection on material already present in breeding and deployment populations, using new trials that now include wood quality information. Another related scenario is clonal forestry. There is a large number of clones already tested for growth and form, but that are just starting to be tested for wood quality traits in new trials.

Overall, this approach changes the target for breeding from trying to produce the best possible wood to produce, much more quickly, acceptable-quality wood. The latter is more realistic and could become a more profitable alternative for breeding programs.

Acknowledgements: Many thanks to Prof. John C.F. Walker and Dr Shakti Chauhan for comments and ideas that contributed to this review. Thanks to Dr Paul Jefferson for providing access to several RPBC data sets and Dr Keith Mackie for access to a WQI data set. 
Many thanks to the anonymous reviewers for their helpful comments. That work was partly funded by the New Zealand RPBC.

\section{REFERENCES}

Apiolaza L.A., 2008. Improvement objectives for short rotation forestry. New Zeal. J. For. 52: 28-30.

Apiolaza L.A. and Garrick D.J., 2001. Analysis of longitudinal data from progeny tests: some multivariate approaches. For. Sci. 47: 129-140.

Apiolaza L.A. and Greaves B.L., 2001. Why are most breeders not using economic breeding objectives? In: IUFRO Conference developing the Eucalypt of the Future, Valdivia, Chile.

Apiolaza L.A., Raymond C.A., and Yeo B.J., 2005. Genetic variation of physical and chemical wood properties of Eucalyptus globulus. Silvae Genet. 54: 160-166.

Apiolaza L.A., Walker J.C.F., Nair H., and Butterfield B.G., 2008. Very early screening of wood quality for radiata pine: pushing the envelope. In: Proceedings of the 51st international convention of society of wood science and technology, WQ-1.

Balocchi C.E., Bridgwater F.E., Zobel B.J., and Jahromi S., 1993. Age trends in genetic parameters for tree height in a nonselected population of loblolly pine. For. Sci. 39: 231-251.

Binet F.E., 1965. On the construction of an index for indirect selection. Biometrics 21: 291-299.

Burdon R.D., Kibblewhite R.P., Walker J.C.F., Megraw R.A., Evans R., and Cown D.J., 2004. Juvenile versus mature wood: a new concept, orthogonal to corewood versus outerwood, with special reference to Pinus radiata and $P$ taeda. For. Sci. 50: 399-415.

Calus M.P.L., Meuwissen T.H.E., de Roos A.P.W., and Veerkamp R.F., 2008. Accuracy of genomic selection using different methods to define haplotypes. Genetics 178: 553-561.

Cave I.D., 1968. The anisotropic elasticity of the plant cell wall. Wood Sci. Technol. 2: 269-278.

Chauhan S.S., 2008. Pairing test and longitudinal growth strain: establishing the association. In: proceedings of the 51st international convention of society of wood science and technology, WQ-2.

Chauhan S.S. and Walker J.C.F., 2006. Variations in acoustic velocity and density with age, and their relationship in radiata pine. For. Ecol. Manage. 229: 388-394.

Dungey H.S., Matheson A.C., Kain D., and Evans R., 2006. Genetics of wood stiffness and its component traits in Pinus radiata. Can. J. For. Res. 36: 1165-1178.

Evans R. and Ilic J., 2001. Rapid prediction of wood stiffness from microfibril, angle and density. For. Prod. J. 51: 53-57.

Fernando R.L. and Grossman M., 1989. Marker assisted selection using best linear unbiased prediction. Genet. Sel. Evol. 21: 467-477.

Fernando R.L., Habier D., Stricker C., Dekkers J.C.M., and Totir L.R., 2007. Genomic selection. Acta Agr. Scand. A - An. 57: 192-195.

Floyd S.L. and Stanish M.A., 2004. Methods for quantitatively determining lengthwise shrinkage in wood products. US Patent Application 10814767.

Gaunt D., 1998. If you are not winning change the rules. New Zeal. For. Res. Wood Proc. Newsletter 23: 3.

Gianola D., Fernando R.L., and Stella A., 2006. Genomic-assisted prediction of genetic value with semiparametric procedures. Genetics 173: 1761-1776.
Gibson J.P., 1999. Molecular and quantitative genetics: a useful flirtation. In: from Jay Lush to Genomics: Visions for animal breeding and genetics, Iowa State University, Ames, Iowa, USA, pp. 77-84.

Gilmour A.R., Cullis B.R., Welham S.J., and Thompson R., 2002. ASReml reference manual. New South Wales Agriculture, Orange, NSW, Australia.

Grattapaglia D. and Kirst M., 2008. Eucalyptus applied genomics: from gene sequences to breeding tools. New Phytol. 179: 911-929.

Hazel L.N., 1943. The genetic basis for constructing selection indexes. Genetics 28: 476-490.

Huang C.L., Lindström H., Nakada R., and Ralston J., 2003. Cell wall structure and wood properties determined by acoustics - a selective review. Holz Roh. Werkst. 61: 321-335.

Isik F., Gumpertz M., Li B.L., Goldfarb B., and Sun X., 2008. Analysis of cellulose microfibril angle using a linear mixed model in Pinus taeda clones. Can. J. For. Res. 38: 1676-1689.

Isik F. and Li B., 2003. Rapid assessment of wood density of live trees using the resistograph for selection in tree improvement programs. Can. J. For. Res. 33: 2426-2435.

Kumar S., Dungey H.S., and Matheson A.C., 2006. Genetic parameters and strategies for genetic improvement of stiffness in radiata pine. Silvae Genet. 55: 77-84.

Lima J.T., Breese M.C., and Cahalan C.M., 2004. Variation in microfibril angle in Eucalyptus clones. Holzforschung 58: 160-166.

Lin C.Y., 1978. Index selection for genetic improvement of quantitative characters. Theor. Appl. Genet. 52: 49-56.

Lindström H., Harris P., and Nakada R., 2002. Methods for measuring stiffness of young trees. Holz Roh. Werkst. 60: 165-174.

Lopez G.A., Potts B.M., Vaillancourt R.E., and Apiolaza L.A., 2003. Maternal and carry over effects on early growth of Eucalyptus globulus. Can. J. For. Res. 33: 2108-2115.

Megraw R.A., Bremer D., Leaf G., and Roers J., 1999. Stiffness in loblolly pine as a function of ring position and height, and its relationship to microfibril angle and specific gravity. In: IUFRO workshop connection between silviculture and wood quality through modelling approaches and simulation software, La Londe-Les-Maures, France, pp. 341-349.

Meuwissen T.H.E., Hayes B.J., and Goddard M.E., 2001. Prediction of total genetic value using genome-wide dense marker maps. Genetics 157: 1819-1829.

Myszewski J.H., Bridgwater F.E., Lowe W.J., Byram T.D., and Megraw R.A., 2004. Genetic variation in the microfibril angle of loblolly pine from two test sites. Southern J. Appl. For. 28: 196-204.

Nakada R., 2007. Within-tree variation of wood characteristics in conifers and the anatomical characteristics specific to very young trees. In: J.C.F. Walker (Ed.), The compromised wood workshop, Christchurch, New Zealand, 51-67.

Newman D.H. and Williams C.G., 1991. The incorporation of risk in optimal selection age determination. For. Sci. 37: 1350-1364.

O'Malley D.M. and McKeand S.E., 1994. Marker assisted selection for breeding value in forest trees. For. Genet. 1: 207-218.

R Development Core Team, 2008. R: a language and environment for statistical computing. R foundation for statistical computing, Vienna, Austria.

Raymond C.A., 2002. Genetics of Eucalyptus wood properties. Ann. For. Sci. 59: 525-531.

Raymond C.A. and Schimleck L.R., 2002. Development of near infrared reflectance analysis calibrations for estimating genetic parameters for cellulose content in Eucalyptus globulus. Can. J. For. Res. 32: 170176. 
Raymond C.A., Schimleck L.R., Muneri A., and Michell A.J., 2001. Genetic parameters and genotype-by-environment interaction for pulp yield predicted using near infrared reflectance analysis and pulp productivity in Eucalyptus globulus. For. Genet. 8: 213-224.

Schaeffer L.R., 2006. Strategy for applying genome-wide selection in dairy cattle. J. Anim. Breed. Genet. 123: 218-223.

Schimleck L.R., Evans R., Ilic J., and Matheson A.C., 2002. Estimation of wood stiffness of increment cores by near-infrared spectroscopy. Can. J. For. Res. 32: 129-135.

Schimleck L.R., Evans R., Jones P.D., Peter G., Daniels R.F., and Clark A., 2005. Estimation of microfibril angle and stiffness by near infrared spectroscopy using sample sets having limited wood density variation. IAWA J. 26: 175-187.

Schneeberger M., Barwick S.A., Crow G.H., and Hammond K., 1992. Economic indices using breeding values predicted by blup. J. Anim. Breed. Genet. 107: 180-187.

Searle S.R., 1965. The value of indirect selection: I. mass selection. Biometrics 21: 682-707.

Shelbourne C.J.A., 1997. Genetics of adding value to the end-products of radiata pine. In: Burdon R.D. and Moore J.M. (Eds.), IUFRO '97 Genetics of Radiata Pine, Rotorua, New Zealand, 129-141.

Smith D.M., 1954. Maximum moisture content method for determining specific gravity of small wood samples. Report 2014, Forest Products Laboratory, Forest Service, US Department of Agriculture.

Sorensson C.T. and Shelbourne C.J.A., 2005. NZIF Forestry handbook, New Zealand Institute of Forestry, chapter Clonal forestry, pp. 92-96.
Tsehaye A., Buchanan A., and Walker J.C.F., 2000. Sorting of logs using acoustics. Wood Sci. Technol. 34.

Van Vleck L.D., 1993. Selection Index and introduction to mixed model methods. CRC Press, Boca Raton.

Walker J.C.F. and Butterfield B.G., 1995. The importance of microfibril angle for the processing industries. New Zeal. For. 40: 34-40.

White T.L., Adams W.T., and Neale D., 2007. Forest genetics, CAB international.

Wielinga B., Raymond C.A., James R., and Matheson A.C., 2009. Genetic parameters and genotype by environment interactions for green and basic density and stiffness of Pinus radiata d. don estimated using acoustics. Silvae Genet. (in press).

Wilcox P.L., Carson S.D., Richardson T.E., Ball R.D., Horgan G.P., and Carter P., 2001. Benefit-cost analysis of dna marker based-selection in progenies of Pinus radiata seed orchard parents. Can. J. For. Res. 31: 2213-2224.

Woolaston R.R. and Jarvis S.F., 1995. The importance of breeding objectives in forest tree improvement. In: Eucalypt plantations: improving fibre yield and quality, Hobart, Tasmania, Australia, 184-188.

Wu H.X., Powell M.B., Yang J.L., Ivkovich M., and McRae T.A., 2007. Efficiency of early selection for rotation-aged wood quality traits in radiata pine. Ann. For. Sci. 64: 1-9.

Yamashita K., Hirakawa Y., Nakatani H., and Ikeda M., 2009. Longitudinal shrinkage variations within trees of sugi (Cryptomeria japonica) cultivars. J. Wood Sci. 55: 1-7.

Zamudio F., Baettyg R., Vergara A., Guerra F., and Rozenberg P., 2002. Genetic trends in wood density and radial growth with cambial age in a radiata pine progeny test. Ann. For. Sci. 59: 541-549. 